\title{
Fast-track protocols in devascularization for cirrhotic portal hypertension
}

\author{
Yang Fei ${ }^{1 *}$, Guang-Quan Zong ${ }^{2 *}$, Jian Chen ${ }^{3}$, Ren-min Liu ${ }^{4}$ \\ ${ }^{1}$ M.D - Professor. Department of General Surgery, the $81^{\text {st }}$ Hospital of PL.A., Nanjing,China \\ ${ }^{2}$ M.D - Professor. Department of General Surgery, the $81^{\text {st }}$ Hospital of P.L.A., Nanjing,China \\ ${ }^{3}$ M.D - Professor. Department of General Surgery, the $81^{\text {st }}$ Hospital of P.L.A., Nanjing, China \\ ${ }^{4}$ M.D - Professor. Department of General Surgery, the $81^{\text {st }}$ Hospital of P.L.A., Nanjing,China
}

\begin{abstract}
SUMmaRY
Study conducted at the $81^{\text {st }}$ Hospital of P.L.A, Nanjing, China

Article received: $7 / 27 / 2014$ Accepted for publication: 10/22/2014

*Correspondence: Address: 34 Biao Lane Nanjing - China Postal code: 210000 fei_yanggood@163.com

http://dx.doi.org/10.1590/1806-9282.61.03.250 Conflict of interest: none

Introduction/objective: fast-tract surgery (FTS) has been rapidly embraced by surgeons as a mechanism for improving patient care and driving down complications and costs. The aim of this study was to determine if any improvement in outcomes occurred after FTS protocol for selective double portazygous disconnection with preserving vagus (SDPDPV) compared with non-FTS postoperative care. Methods: patients eligible for SDPDPV in the period January 2012-April 2014 were randomly selected for the FTS group or non-FTS group. A designed protocol was used in the FTS group with emphasis on an interdisciplinary approach. The non-FTS group was treated using previously established standard procedures. The number of postoperative complications, time of functional recovery and duration of hospital stay were recorded.

Results: patients in the FTS group $(\mathrm{n}=59)$ and non-FTS group ( $\mathrm{n}=57)$ did not differ in terms of preoperative data and operative details ( $p>0.05$ ). The FTS procedure led to significantly better control and faster restoration of gastrointestinal functions, food tolerance, rehabilitation and hospital discharge ( $\mathrm{p}<0.05)$. Postoperative complications, including nausea/vomiting, severe ascites, wound infection, urinary tract infection and pulmonary infection were all significantly lower in the FTS group ( $\mathrm{p}<0.05)$. According to the postoperative morbidity classification used by Clavien, overall complications and grade I complications were both significantly lower in the FTS group compared with the non-FTS group $(\mathrm{p}<0.05)$.

Conclusion: adopting the FTS protocol helped to recover gastrointestinal functions, to reduce frequency of postoperative complications and to reduce hospital stay. The FTS strategy is safe and effective in improving postoperative outcomes.

Keywords: medicare, portal hypertension, postoperative care, protocols, length of stay.

\section{INTRODUCTION}

As a care strategy introduced to facilitate earlier discharge, fast-track surgery (FTS) programs, described by Kehlet et al., ${ }^{1}$ have been developed by combining anesthesic management, innovational surgical technique, pre-/intra-/ post-operative management and nursing. ${ }^{2-5}$ Recently, FTS were applied to major surgeries, including colectomy, hepatectomy and urologic procedures to greatly accelerate recovery, limit physiologic stress response, reduce morbidity and shorten hospital stay or hospital cost of surgical patients. ${ }^{6-8}$ Despite the clear benefit of FTS proto-

cols in these surgeries, the combination between surgery and FTS protocols for cirrhotic portal hypertension (PHT) has not been well studied.

\section{Objective}

The aim of this study was to determine if any improvement in short-term outcomes occurred with the institution of an FTS protocol for selective double portazygous disconnection with preserving vagus (SDPDPV) (a modified devascularization), when compared with conventional non-FTS postoperative care.
\end{abstract}




\section{Methods}

\section{Patients and study design}

This prospective, monocentric, unblinded, randomized study included 193 patients who underwent SDPDPV from January 2012 to April 2014. All eligible patients were enrolled in the study. The inclusion criteria were: (1) SDPDPV for PHT; (2) not combined with hepatic tumor; (3) without severe cardiopulmonary disease; (4) Child-Pugh score $<10$. Patients fulfilling inclusion criteria and consenting to participate in the study were randomized into one of two groups: FTS (63 patients) and non-FTS (62 patients). Simple unrestricted randomization using the standard envelope method was performed. Randomization was done by a nurse who was not involved in this study, when the patients were considered suitable to be included. Numbered envelopes containing a sequence of included patients determined their random distribution into the FTS or non-FTS groups. According to the envelope content, the patient was assigned to one of the monitored groups on the day of admission.

The preoperative evaluation and preparation for anesthesia and surgery consisted of standard liver function tests, and preoperative endoscopic and ultrasonographic evaluations. Decisions on the patients' treatment strategies were multidisciplinary. Patients' demographics, body mass index (BMI), American Society of Anesthesiologists (ASA) grades, diagnoses, liver function tests and details of surgical procedures were recorded. The number of postoperative complications, time of functional recovery and duration of hospital stay were studied as well. Clavien grading, which ranks complications based on therapeutic consequences was used. ${ }^{9}$

The study was approved by the institutional review board of the $81^{\text {st }}$ Hospital of P.L.A. Patient's decision to participate in the study was voluntary, and informed consent was obtained for randomization and treatment.

\section{Surgical technique}

The technique of SDPDPV was applied as described by Zong et al..$^{10}$ The same operative setup and standardized technique were applied for all patients. Procedures were performed by the same team of specialists in gastrointestinal and hepatobiliary surgery.

\section{FTS and non-FTS group protocol}

The FTS protocol in our institution consisted of pre/intro/postoperative management, and its details are shown in Table 1.

Patients randomized into the non-FTS group were instructed in the standard manner. Conventional information on PHT were informed to the patients. Preop- erative respiratory physiotherapy was not offered to them. Four hours before operation, avoidance of oral fluid intake was carried out. Antibiotic prophylaxis was not performed in the patients. During the course of operation, ultrasound knife and reabsorbable clips were not used for dissection and vessel ligation. Patients had a feeding tube inserted if they agreed to this process, and they fasted from the midnight before surgery. The type of anesthesia was general anesthesia. Postoperative analgesia comprised continuous epidural analgesia using local anesthetics combined with epidural morphine or subcutaneous morphine. Both methods were supplemented by bolus administration of metamizol or diclofenac. Insertion of gastric drainage tube, intra-abdominal drains and urinary catheter was routine. Postoperative oral intake and rehabilitation proceeded in the standard manner.

\section{HoSPITAL DISCHARGE CRITERIA}

Patients were fit for discharge when they had met the following criteria, according to Fearon and our experience: ${ }^{11}$

1. Return of bowel function, passage of flatus or stool;

2. Tolerance of fluids and solid diet;

3. Pain control via oral analgesic;

4. Adequate patient mobility;

5. Wound healed well without seroma;

6. Curing hypersplenism and/or upper gastrointestinal hemorrhage;

7. Being happy to be discharged with adequate home support.

Discharge criteria were the same in both groups and at all time periods during this study.

\section{Statistical analysis}

Continuous data were described as medians (range) and analyzed with Student's $t$-test. Categorical data were described as numbers and percentages and analyzed using Chi-square test. A p-value of less than 0.05 was considered statistically significant. Statistical analysis was performed using statistical package for the social sciences Categorical data version 15.0 (SPSS Inc., Chicago, IL, USA).

\section{RESULTS}

\section{Clinical characteristics}

All patients underwent SDPDPV for PHT successfully. Four patients from the FTS group and five patients from non-FTS group were excluded owing to discontinued intervention and they were not analyzed. A total of $59 \mathrm{pa}-$ 
tients were analyzed in the FTS group and 57 patients in the control non-FTS group.

Baseline demographic characteristics of the two groups are shown in Table 1. There were no significant difference between the groups with respect to age, gender, BMI, ASA grades, Child-Pugh's score, variceal grade, alanine aminotransferase (ALT) and hemoglobin $(\mathrm{Hb})(\mathrm{p}<0.05)($ Table 2).

\section{TABLE1 Fast-track surgery program of patients.}

\section{Preoperative management}

1. Detailed information given to the patient regarding the therapeutic course, preoperative patient education focusing on recovery expectations

2. Preoperative respiratory physiotherapy

3. Avoidance oral fluid intake 12 hours before operation

\section{Intraoperative management}

1. Keep warm temperature in the operating room, warm normal saline to wash the abdominal cavity, and drip administration at a controlled temperature

2. Ultrasound knife and reabsorbable clips were used for dissection and vessel ligation

3. Antibiotic prophylaxis

4. Anesthetic protocol: insertion of epidural catheter (level T8-T9)

5. Adjusted hydration: replacement of blood loss and imperceptible loss at the rate of $6-8 \mathrm{~mL} / \mathrm{kg} / \mathrm{h}$

6. Control infusion fluid, especially excessive crystalloid solution

Postoperative protocol

1. Catheter with local anesthetics in continued perfusion, and removal of epidural analgesia 48 hours postoperatively

2. Respiratory physiotherapy and atomizing inhalation of Ambroxol during the first 72 hours

3. Removal of the abdominal drains after 48 hours if no more bloody fluid is observed

4. Discontinuation of gastric decompression by 8 a.m. the day after surgery

5. Patients are encouraged to drink immediately after recovery from anesthesia. After flatus and oral tolerance is reached, a gradual transition from semi-liquid diet to soft diet/low fiber solid food

6. Removal of foley catheter on the third postoperative day

7. Intravenous injection furosemide ( $20 \mathrm{mg} / \mathrm{q}$.d) .during the first 72 hours. Thereafter, change to oral furosemide ( $20 \mathrm{mg}$ b.i.d.).

8. Prokinetic and somatostatin

9. Mobility, as much as possible from the first postoperative day (moving patients to a chair)

10. An emphasis on minimization of intravenous fluids to keep patients at their baseline weight.

11. Supplement plasma or human albumin on the basis of liver function and albumin values discretionarily to maintain concentration of serum albumin not less than $30 \mathrm{~g} / \mathrm{L}$
TABLE 2 Baseline patient demographics.

\begin{tabular}{llll} 
Demographics & FTS $(\mathbf{n = 5 9 )}$ & Non-FTS $(\mathbf{n}=\mathbf{5 7})$ & P-value \\
\hline Age & & & \\
\cline { 1 - 2 } Mean SD (years) & $46.3-6.9$ & $44.9-8.1$ & 0.297 \\
\hline Gender & & & \multirow{2}{*}{0.185} \\
\cline { 1 - 2 } & 34 & 31 & \\
\cline { 1 - 2 } Female & 25 & 26 &
\end{tabular}

\begin{tabular}{|c|c|c|c|}
\hline \multicolumn{4}{|l|}{ BMI } \\
\hline Mean SD $\left(\mathrm{Kg} / \mathrm{m}^{2}\right)$ & $29.5-5.8$ & $30.3-6.1$ & 0.422 \\
\hline \multicolumn{4}{|l|}{ ASA grades } \\
\hline |-II & 45 & 40 & \multirow[t]{2}{*}{0.230} \\
\hline III-IV & 14 & 17 & \\
\hline Child-Pugh's score & $7.0-1.4$ & $6.9-1.2$ & 0.641 \\
\hline \multicolumn{4}{|l|}{ Variceal grade } \\
\hline | & 18 & 16 & \multirow[t]{3}{*}{0.585} \\
\hline II & 29 & 30 & \\
\hline III & 12 & 11 & \\
\hline $\operatorname{ALT}(I U / L)$ & $27.4-7.1$ & $28.2-6.8$ & 0.592 \\
\hline $\mathrm{Hb}(\mathrm{g} / \mathrm{L})$ & $98.5-18.6$ & $103.3-21.6$ & 0.127 \\
\hline
\end{tabular}

ASA: American Society of Anesthesiologists; BMI: body mass index; FTS: Fast-track surgery.

\section{Intraoperative data}

There were no significant differences in the operative details, including operative time and intraoperative blood loss between the FTS group and the non-FTS group $(\mathrm{p}=0.314, \mathrm{p}=0.395)$. The difference of free portal pressure (FPP) between the two groups were not significant before splenectomy and after devascularization $(\mathrm{p}=0.261$, $\mathrm{p}=0.192$ ). Furthermore, no difference in the number of patients who had to be transfused was observed between the two groups $(\mathrm{p}=0.868)$ (Table 3 ).

\section{Postoperative data}

None of the patients died in the postoperative course within 30 days, and no patients were readmitted within 30 days of surgery.

Based on the protocol of FTS, the abdominal drain was removed much earlier in the FTS group than in the non-FTS group of patients. The difference was statistically significant $(\mathrm{p}=0.002)$ (Table 4$)$.

Time required for patients to first pass flatus after surgery were significantly shorter in the FTS group than the non-FTS group $(\mathrm{p}=0.021)$. In addition, patients in the FTS group had their first bowel movement almost a full day earlier than those in the non-FT group ( $\mathrm{p}=0.027)$ (Table 4).

Patients in the motivated FTS group were encouraged to drink and eat. In the study, we found that patients in the FTS group were capable of accepting a soft or low fi- 
ber diet (3.9 0.6 days) more quickly than those in the nonFTS group (6.3 1.8 days) $(\mathrm{p}=0.016)$, as recorded in Table 4 .

With respect to length of hospital stay, the patients in the FTS group were discharged from hospital significantly earlier than the non-FTS group $(\mathrm{p}=0.005)$. (Table 4).

\begin{tabular}{|c|c|c|c|}
\hline Demographic & $\begin{array}{l}\text { FTS } \\
(n=59)\end{array}$ & $\begin{array}{l}\text { Non-FTS } \\
(n=57)\end{array}$ & P-value \\
\hline Operative time (min) & $242.1-69.7$ & $232.5-72.2$ & 0.314 \\
\hline $\begin{array}{l}\text { Intraoperative blood loss } \\
(\mathrm{mL})\end{array}$ & $569.5-62.1$ & $581.2-74.9$ & 0.395 \\
\hline $\begin{array}{l}\text { FPP before splenectomy } \\
(\mathrm{mmHg})\end{array}$ & $36.9-3.6$ & $38.2-3.5$ & 0.261 \\
\hline $\begin{array}{l}\text { FPP after devascularization } \\
(\mathrm{mmHg})\end{array}$ & $22.4-3.2$ & $23.8-3.6$ & 0.192 \\
\hline Patients transfused, n (\%) & 3 & 4 & 0.868 \\
\hline
\end{tabular}

\section{TABLE 4 Short-term operative outcomes.}

\begin{tabular}{llll} 
Outcomes (mean SD) & $\begin{array}{l}\text { FTS } \\
(\mathbf{n = 5 9 )})\end{array}$ & $\begin{array}{l}\text { Non-FTS } \\
(\mathbf{n}=\mathbf{5 7})\end{array}$ & p-value \\
\hline $\begin{array}{l}\text { Duration of abdominal drain } \\
\text { (days) }\end{array}$ & $2.6-1.9$ & $5.8-2.4$ & 0.002 \\
\hline Duration to first flatus (days) & $1.7-0.5$ & $2.8-0.7$ & 0.021 \\
\hline $\begin{array}{l}\text { Duration to first bowel } \\
\text { movement (days) }\end{array}$ & $4.1-1.4$ & $6.0-1.5$ & 0.027 \\
\hline $\begin{array}{l}\text { Duration to tolerating soft/low } \\
\text { fiber diet (days) }\end{array}$ & $3.9-0.6$ & $6.3-1.8$ & 0.016 \\
\hline Length of hospital stay (days) & $17.3-5.5$ & $23.6-7.3$ & 0.005 \\
\hline FTS: fast-track surgery. & & & \\
\hline
\end{tabular}

\section{Postoperative complications}

By univariate analysis, infectious complications including wound infection, urinary tract infection, pulmonary infection and intraperitoneal abscess were recorded (Table 5). The wound infection rates for the FTS group versus non-FTS group were 13.6 and $24.6 \%$, respectively $(\mathrm{p}=0.022)$. The difference of urinary tract infection and pulmonary infection between the two groups was significant ( $\mathrm{p}=0.017, \mathrm{p}=0.002)$. However, intraperitoneal abscess was not different between the two recovery protocols $(\mathrm{p}=1.000)$. There was significantly less nausea and vomiting in the FTS group $(n=4)$ as compared to the nonFTS group postoperatively $(\mathrm{n}=1)(\mathrm{p}=0.009)$. Surgical complications correlated with PHT, and encephalopathy and postoperative liver failure were not different between the two recovery protocols $(p>0.05)$. However, severe ascites developed in one patient (1.7\%) who underwent the FTS protocol and in three patients (5.3\%) treated with nonFTS protocol; the difference between the two groups was significant $(\mathrm{p}=0.006)$. Other complications, including non-infectious pulmonary complications, cardiac complications, prolonged ileus, pleural effusion and hemorrhage (requiring transfusion) were similar in both recovery protocols $(\mathrm{p}>0.05)$.

Overall complications according to the postoperative morbidity classification used by Clavien are shown in Table 5; they were significantly lower in the FTS group (25.4\%, $15 / 59)$ compared with the non-FTS group (42.1\%, 24/57), $(\mathrm{p}=0.008)$. Grade I complications were much less frequent in the FTS group $(11.9 \%, 7 / 59)$ compared with the nonFTS group $(26.3 \%, 15 / 57)(\mathrm{p}=0.005)$. Grade II postoperative complications in FTS group and non-FTS group were $5.1 \%(3 / 59)$ versus $5.3 \%(3 / 57)$, respectively $(\mathrm{p}=1.000)$. The result of grade III complications was similar to that of grade II ( $\mathrm{p}=0.892)$. There were no grade IIIb, IVa, IVb and V complications in any of the two groups (Table 5).

\section{TABLE 5 Postoperative complications.}

\begin{tabular}{|c|c|c|c|}
\hline Groups & $\begin{array}{l}\text { FTS } \\
(n=59)\end{array}$ & $\begin{array}{l}\text { Non-FTS } \\
(n=57)\end{array}$ & p-value \\
\hline $\begin{array}{l}\text { Hemorrhage requiring } \\
\text { transfusion, } \mathrm{n}(\%)\end{array}$ & $2(3.4 \%)$ & $2(3.5 \%)$ & 1.000 \\
\hline Intraperitoneal abscess & $2(3.4 \%)$ & $2(3.5 \%)$ & 1.000 \\
\hline Severe ascites & $1(1.7 \%)$ & $3(5.3 \%)$ & 0.006 \\
\hline Encephalopathy & $4(6.8 \%)$ & $4(7.0 \%)$ & 1.000 \\
\hline Postoperative liver failure & $3(5.1 \%)$ & $2(3.5 \%)$ & 0.861 \\
\hline Prolonged ileus, n (\%) & $2(3.4 \%)$ & $2(3.5 \%)$ & 1.000 \\
\hline Pleural effusion, n (\%) & $2(3.4 \%)$ & $3(5.3 \%)$ & 0.827 \\
\hline Pulmonary infection, $\mathrm{n}(\%)$ & $1(1.7 \%)$ & $5(8.8 \%)$ & 0.002 \\
\hline $\begin{array}{l}\text { Non- infectious pulmonary } \\
\text { complications, } \mathrm{n}(\%)\end{array}$ & $2(3.4 \%)$ & $1(1.8 \%)$ & 0.662 \\
\hline Cardiac complications, n (\%) & $2(3.4 \%)$ & $2(3.5 \%)$ & 1.000 \\
\hline Wound infection, n (\%) & $8(13.6 \%)$ & $14(24.6 \%)$ & 0.022 \\
\hline Urinary tract infection, n (\%) & $4(6.8 \%)$ & $7(12.3 \%)$ & 0.017 \\
\hline Nausea/vomiting n (\%) & $4(6.8 \%)$ & $11(19.3 \%)$ & 0.009 \\
\hline \multicolumn{4}{|l|}{ Clavien classification } \\
\hline Overall complications & 15 & 24 & 0.008 \\
\hline Grade I & 7 & 15 & 0.005 \\
\hline Grade II & 3 & 3 & 1.000 \\
\hline Grade III a & 5 & 6 & 0.892 \\
\hline Grade III b ,IV a, IV b, V & 0 & 0 & NS \\
\hline
\end{tabular}

\section{Discussion}

FTS is a multidisciplinary approach aimed at minimizing perioperative stress determinants to reduce postop- 
erative complications and the time of recovery until "daily normal activities" can be resumed. ${ }^{12}$ Evidence in fast-track surgery suggests that it is associated with a reduction in costs and risk of medical complications. ${ }^{13}$ Since the early 1990s, minimally invasive surgical approaches have been investigated heavily in addition to anesthesiology stress-free techniques and postoperative fast rehabilitation programs. ${ }^{14,15}$ However, utilizations of FTS approach in portal hypertension surgery to improve outcomes, reduce postoperative complications, and reduce the length of hospital stay were not extensive; the benefits of fast-track portal hypertension surgery are not well recognized. In our study, we found that the FTS group had a significantly improved speed of gastrointestinal recovery with respect to time to tolerate soft/low fiber diet, first flatus and first bowel movement. More importantly, this group showed decreased morbidity and a shorter hospital stay, which is consistent with data from other FTS literature. ${ }^{16-18}$

The key to FTS was reducing stress to patients. Patients can benefit from evaluation and education to reduce stress preoperatively. ${ }^{19}$ After receiving perioperative information, patients could understand the aim to FTS protocol and course of treatment. Thus, patients would not only feel relaxed, without fear or anxiety, but also be in favor of FTS protocol. Better patient cooperation brings better recovery outcomes. A successful FTS program requires the formation of a multidisciplinary team consisting of surgeons, anesthesiologists and nurses. The team requires full commitment of all individuals to perform the specific tasks of the FTS program. Specialized nurses may even reduce mortality and failure-to-rescue rates. ${ }^{20}$

Insulation in the operating room can prevent stress from rewarming after hypothermia which might lead to blood coagulation dysfunction and reperfusion injury. Proper analgesia not only can reduce the pain-related stress response, but also increase the confidence of patients to overcome the disease. ${ }^{21}$

It has been verified that patients who suffer from less postoperative nausea and vomiting normally have earlier recovery of ileus and shorter length of hospital stay. ${ }^{22-}$ ${ }^{24}$ However, many factors influence the incidence of postoperative nausea and vomiting. The use of volatile anesthetics, nitrous oxide ${ }^{25}$ and intra/post-operative opioids are risk factors related to anaesthesia. ${ }^{26,27}$ One component we could influence was the choice of anesthesia. Epidural anesthesia was used in FTS group to exclude the effect from volatile components. Starvation and thirst are potential risk factors of postoperative nausea and vomiting that need to be further investigated..$^{28}$ Our peri- operative design also aimed to minimize these influences (e.g. avoiding preoperative oral fluid intake and early postoperative oral intake of both fluid and food). Longterm indwelling gastric tube is another risk factor, ${ }^{29}$ so discontinuation of gastric decompression by 8 a.m. the day after surgery was performed in the FTS group. The results showed that there was significantly less nausea and vomiting in the FTS group as compared to the non-FTS group. Early enforced mobilization is a critical step in the FTS protocol. To have a successful early mobilization, adequate pain control and good nursing care are important. Epidural catheter with local anesthetics in continued perfusion allows patients to move soon after surgery. A good FTS protocol can result in significantly less stress, less postoperative complication and better comfort for patients after surgery. Patients who suffer from less postoperative nausea and vomiting normally have earlier recovery of ileus and shorter length of hospital stay. ${ }^{30,31}$

Postoperative infection was one of the most important reasons that could increase the length of hospital stay. ${ }^{32,33}$ It is well known that moving as much as possible postoperatively not only promotes gastrointestinal motility and reduces the incidence of urinary retention, but also accelerates recovery of lung function and wound healing. ${ }^{30,34,35}$ Then, the rate of pulmonary, urinary tract and wound infection would decrease. Based on that, patients in the FTS group were encouraged to perform ambulation early. Wichmann et al. found that FTS led to a better-preserved cell-mediated immune function ( $T$ cells, T-helper cells, natural killer cells), while the proinflammatory response (C-reactive protein, interleukin-6) remained unchanged. ${ }^{36}$ It was beneficial to promote wound healing and reduce the probability of infection. In our study, the difference of wound infection, urinary tract infection and pulmonary infection in the FTS group versus non-FTS group was significant. Furthermore, early removal of foley catheter and respiratory physiotherapy/atomizing inhalation of Ambroxol in FTS group can also reduce infection in the urinary and respiratory tracts.

Ascites was sometimes difficult to be controlled postoperatively. ${ }^{37}$ The mechanisms include a high hydrostatic pressure of portal hypertension leading to increased production and transudation of hepatic and splanchnic lymph into the peritoneal cavity. The ascitogenic effect of dissection with lymphatic interruption may also explain the higher rate of early postoperative ascites after operation. ${ }^{38,39}$ Especially severe ascites can reduce patients' blood volume and organ perfusion, and, thus, liver and kidney function 


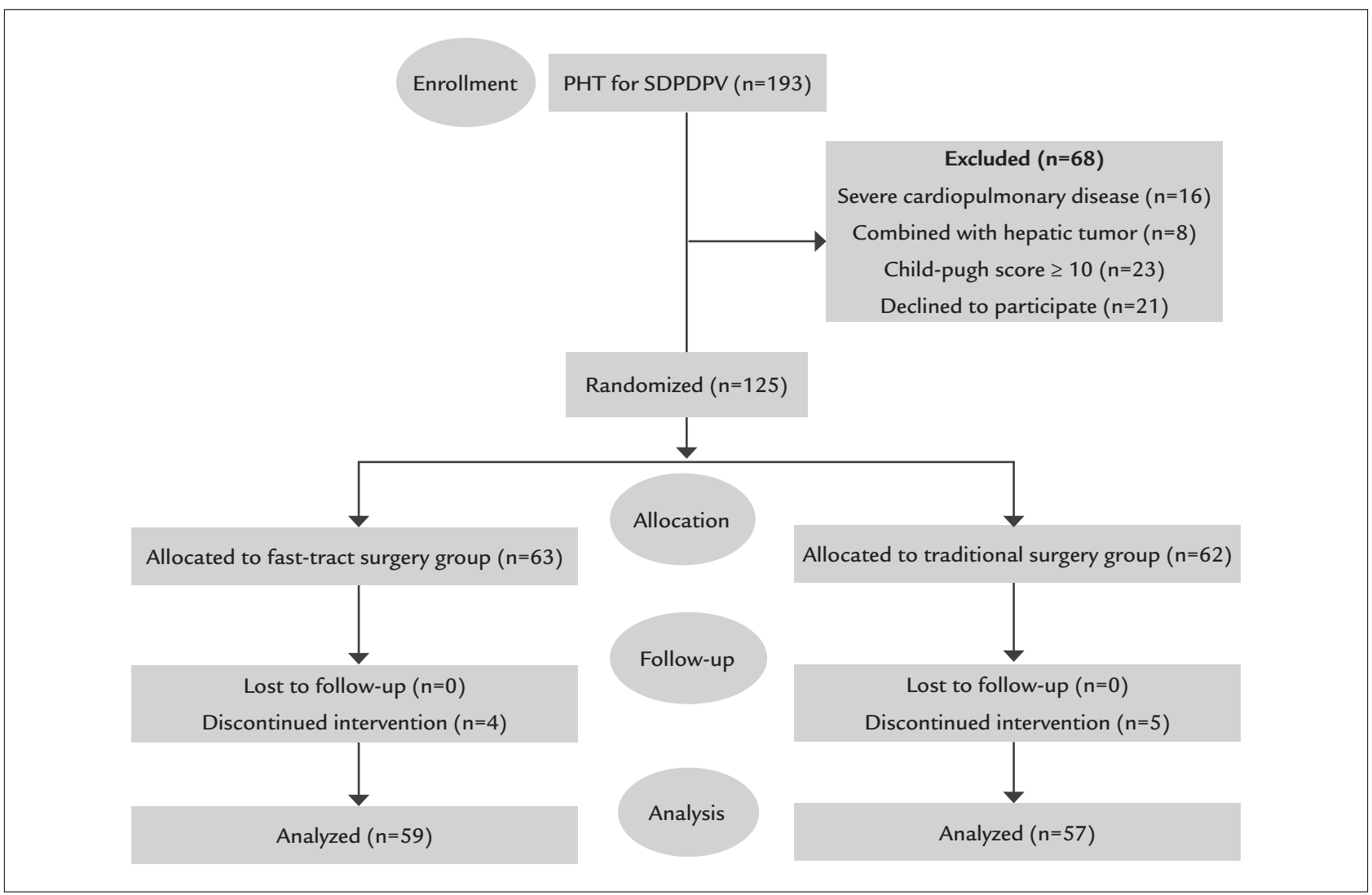

FIGURE 1 Flowchart of participants through each stage.

might be damaged. So, we tried to control ascites postoperatively by using diuretics and supplying human albumin at an early stage. This was beneficial for patients on early ambulation, recovering their gastrointestinal function.

In our study, grade I postoperative complications, which needn't pharmaceutical treatment or any other interventions, could be reduced by FTS protocol. The appearance of complications had significant implications for the length of hospitalization. So FTS protocol could effectively reduce the length of hospitalization.

FTS is an ongoing conducted, and can be improved at all times. For example, laparoscopic procedure on devascularization and splenectomy has been commended. ${ }^{40}$ For an experienced surgeon, laparoscopic SDPDPV is safe with acceptable morbidity and mortality. Laparoscopic SDPDPV can significantly reduce stress response, speed up the rehabilitation of patients and lead to shorter length of hospital stay after surgery. However, in this study, we only compared open SDPDPV with or without FTS program. Further studies are needed with a focus on the influence of laparoscopic SDPDPV with FTS program after surgery.

\section{Conclusion}

Rehabilitation using the FTS protocol was faster compared with non-FTS protocol after SDPDPV. Gastrointestinal function was also restored sooner, which may be associated with forced early oral intake, and more frequent time spent out of bed. Lower frequency of postoperative complications may be the result of significantly less use of intervention inlets in the FTS group. Furthermore, FTS procedures led to significantly shorter hospital stays. The FTS strategy is safe and effective in improving postoperative outcomes.

\section{Resumo}

Protocolos rápidos em desvascularização para hipertensão portal por cirrose.

Objetivo: a cirurgia fast-track (FTS) foi rapidamente abraçada por cirurgiões como um mecanismo para melhorar o atendimento ao paciente e reduzir complicações e custos. O objetivo deste estudo foi determinar se qualquer melhoria nos resultados de um protocolo FTS para des- 
conexão seletiva dupla porta (SDPDPV), quando comparado ao cuidado pós-operatório não FTS.

Métodos: pacientes candidatos a SDPDPV, no período de janeiro de 2012 a abril de 2014, foram selecionados aleatoriamente para o grupo FTS ou grupo não FTS. Um protocolo projetado foi utilizado no grupo FTS, com ênfase em uma abordagem interdisciplinar. O grupo não FTS foi tratado por meio de procedimentos padrão, estabelecidos previamente. O número de complicações pós-operatórias, o tempo de recuperação funcional e o tempo de internação hospitalar foram registrados.

Resultados: os pacientes do grupo de FTS ( $\mathrm{n}=59$ ) e grupo não FTS ( $\mathrm{n}=57)$ não diferiram em termos de dados pré-operatórios e detalhes cirúrgicos $(\mathrm{p}>0,05)$. O procedimento FTS levou à melhora significativa do controle e à restauração mais rápida das funções gastrointestinais, tolerância alimentar, reabilitação e alta hospitalar $(\mathrm{p}<0,05)$. Complicações pós-operatórias, incluindo náuseas/vômitos, ascite grave, infecção da ferida, infecção urinária e infecção pulmonar foram significativamente menores no grupo FTS $(\mathrm{p}<0,05)$. De acordo com a classificação de morbidade pós-operatória utilizado por Clavien, complicações gerais e complicações de classe I foram ambas significativamente mais baixas no grupo de FTS em comparação com o grupo não FTS ( $\mathrm{p}<0,05)$.

Conclusão: a adoção do protocolo FTS ajudou a recuperar as funções gastrointestinais, reduzir a frequência de complicações pós-operatórias e reduzir tempo de internação hospitalar. A estratégia FTS é segura e eficaz para melhorar os resultados pós-operatórios.

Palavras-chave: medicare, hipertensão portal, cuidados pós-operatórios, protocolos, tempo de internação.

\section{References}

1. Bardram L, Funch-Jensen P, Jensen P, Crawford ME, Kehlet H. Recovery after laparoscopic colonic surgery with epidural analgesia, and early oral nutrition and mobilisation. Lancet. 1995; 345(8952):763-4.

2. Veenhof AA, Vlug MS, van der Pas MH, Sietses C, van der Peet DL, de Langede Klerk ES, et al. Surgical stress response and postoperative immune function after laparoscopy or open surgery with fast track or standard perioperative care: a randomized trial. Ann Surg. 2012; 255(2):216-21.

3. Zargar-Shoshtari K, Paddison JS, Booth RJ, Hill AG. A prospective study on the influence of a fast-track program on postoperative fatigue and functional recovery after major colonic surgery. J Surg Res. 2009; 154(2):330-5.

4. Muehling B, Schelzig H, Steffen P, Meierhenrich R, Sunder-Plassmann L, Orend $\mathrm{KH}$. A prospective randomized trial comparing traditional and fasttrack patient care in elective open infrarenal aneurysm repair. World J Surg. 2009; 33(3):577-85.

5. Hübner M, Schäfer M, Demartines N, Müller S, Maurer K, Baulig W, et al. Impact of restrictive intravenous fluid replacement and combined epidural analgesia on perioperative volume balance and renal function within a Fast Track program. J Surg Res. 2012; 173(1):68-74.

6. Mechet-Boillot I, Bongiovanni JP. [Fast tract rehabilitation in colonic surgery]. Ann Chir. 2005; 130(3):141-3.
7. van Dam RM, Hendry PO, Coolsen MM, Bemelmans MH, Lassen K, Revhaug $\mathrm{A}$, et al. Initial experience with a multimodal enhanced recovery programme in patients undergoing liver resection. Br J Surg. 2008; 95(8):969-75.

8. Raue W, Haase O, Junghans T, Scharfenberg M, Müller JM, Schwenk W. 'Fast-track' multimodal rehabilitation program improves outcome after laparoscopic sigmoidectomy: a controlled prospective evaluation. Surg Endosc. 2004; 18(10):1463-8.

9. Clavien PA, Barkun J, de Oliveira ML, Vauthey JN, Dindo D, Schulick RD, et al. The Clavien-Dindo classification of surgical complications: five-year experience. Ann Surg. 2009; 250(2):187-96

10. Zong GQ, Fei Y, Chen J, Liu RM. Selective double disconnection for cirrhotic portal hypertension. J Surg Res. 2014; 192(2):383-9.

11. Fearon KC, Ljungqvist O, Von Meyenfeldt M, Revhaug A, Dejong CH, Lassen $\mathrm{K}$, et al. Enhanced recovery after surgery: a consensus review of clinical care for patients undergoing colonic resection. Clin Nutr. 2005; 24(3):466-77.

12. Kehlet H, Wilmore DW. Fast-track surgery. Br J Surg. 2005; 92(1):3-4.

13. Kehlet H, Wilmore DW. Evidence-based surgical care and the evolution of fast-track surgery. Ann Surg. 2008; 248(2):189-98.

14. Carli F, Kehlet H, Baldini G, Steel A, McRae K, Slinger P, et al. Evidence basis for regional anaesthesia in multidisciplinary fast-track surgical care pathways. Reg Anesth Pain Med. 2011; 36(1):63-72.

15. Kehlet H. Multimodal approach to control postoperative pathophysiology and rehabilitation. Br J Anaesth. 1997; 78(5):606-17.

16. Larson DW, Batdorf NJ, Touzios JG, Cima RR, Chua HK, Pemberton JH, et al. A fast-track recovery protocol improves outcomes in elective laparoscopic colectomy for diverticulitis. J Am Coll Surg. 2010; 211(4):485-9.

17. Jakobsen DH, Sonne E, Andreasen J, Kehlet H. Convalescence after colonic surgery with fast-track vs conventional care. Colorectal Dis. 2006; 8(8):683-7.

18. Basse L, Thorbøl JE, Løssl K, Kehlet H. Colonic surgery with accelerated rehabilitation or conventional care. Dis Colon Rectum. 2004; 47(3):271-7; discussion 277-8. Erratum in: Dis Colon Rectum. 2005; 48(8):1673. Dis Colon Rectum. 2004; 47(6):951.

19. Wilmore DW. From Cuthbertson to fast-track surgery: 70 years of progress in reducing stress in surgical patients. Ann Surg. 2002; 236(5):643-8.

20. Darrab AA, Fan J, Fernandes CM, Zimmerman R, Smith R, Worster A, et al. How does fast track affect quality of care in the emergency department? Eur J Emerg Med 2006; 13(1):32-5.

21. Carrive P, Churyukanov M, Le Bars D. A reassessment of stress-induced "analgesia" in the rat using an unbiased method. Pain. 2011; 152(3):676-86.

22. Kariv Y, Delaney CP, Senagore AJ, Manilich EA, Hammel JP, Church JM, et al. Clinical outcomes and cost analysis of a "fast track" postoperative care pathway for ileal pouch-anal anastomosis: a case control study. Dis Colon Rectum. 2007; 50(2):137-46.

23. Farquhar M, Higginson IJ, Booth S. Fast-track trials in palliative care: an alternative randomized controlled trial design. J Palliat Med. 2009; 12(3):213.

24. French JJ, Mansfield SD, Jaques K, Jaques BC, Manas DM, Charnley RM. Fast-track management of patients undergoing proximal pancreatic resection. Ann R Coll Surg Engl. 2009; 91(3):201-4.

25. Apfel CC, Kranke P, Katz MH, Goepfert C, Papenfuss T, Rauch S, et al. Volatile anaesthetics may be the main cause of early but not delayed postoperative vomiting: a randomized controlled trial of factorial design. Br J Anaesth 2002; 88(5):659-68.

26. Junger A, Hartmann B, Benson M, Schindler E, Dietrich G, Jost A, et al. The use of anesthesia information management system for prediction of antiemetic rescue treatment at the postanesthesia care unit. Anesth Analg 2001; 92(5):1203-9.

27. Stadler M, Bardiau F, Seidel L, Albert A, Boogaerts JG. Difference in risk factors for postoperative nausea and vomiting. Anesthesiology. 2003; 98(1):46-52.

28. Palazzo M, Evans R. Logistic regression analysis of fixed patient factors for postoperative sickness: a model for risk assessment. Br J Anaesth 1993; 70(2):135-40

29. Nygren J, Thacker J, Carli F, Fearon KC, Norderval S, Lobo DN, et al. Enhanced Recovery After Surgery (ERAS) Society, for Perioperative Care; European Society for Clinical Nutrition and Metabolism (ESPEN); International Association for Surgical Metabolism and Nutrition (IASMEN). Guidelines for perioperative care in elective rectal/pelvic surgery: Enhanced Recovery After Surgery (ERAS(®)) Society recommendations. World J Surg. 2013; 37(2): 285-305.

30. Padilla Alarcón J, Peñalver Cuesta JC. Experience with lung resection in a fast-track surgery program. Arch Bronconeumol. 2013; 49(3):89-93.

31. Jayne DG, Thorpe HC, Copeland J, Quirke P, Brown JM, Guillou PJ. Fiveyear follow-up of the Medical Research Council CLASICC trial of 
laparoscopically assisted versus open surgery for colorectal cancer. Br J Surg 2010; 97(6):1638-45.

32. Markou T, Chambers DJ. Lung injury after simulated cardiopulmonary bypass in an isolated perfused rat lung preparation: Role of mitogen-activated protein kinase/Akt signaling and the effects of theophylline. J Thorac Cardiovasc Surg. 2014; 148(5): 2335-44.

33. Cogbill TH, Cofer JB, Jarman BT. Contemporary issues in rural surgery. Curr robl Surg. 2012; 49(5):263-318.

34. Ryan AT, Luscombe-Marsh ND, Saies AA, Little TJ, Standfield S, Horowitz $\mathrm{M}$, et al. Effects of intraduodenal lipid and protein on gut motility and hormone release, glycemia, appetite, and energy intake in lean men. Am J Clin Nutr. 2013; 98(2):300-11.

35. Khan S, Wilson T, Ahmed J, Owais A, MacFie J. Quality of life and patient satisfaction with enhanced recovery protocols. Colorectal Dis. 2010; 12(12):1175-82
36. Wichmann MW, Eben R, Angele MK, Brandenburg F, Goetz AE, Jauch KW. Fast-track rehabilitation in elective colorectal surgery patients: a prospective clinical and immunological single-centre study. ANZJ Surg. 2007; 77(7):502-7.

37. Di Carlo I, Toro A. Correct indication for surgery can prevent postoperative ascites in cirrhotic patients affected by hepatocellular carcinoma. World J Surg. 2012; 36(7):1719-20.

38. Hoekstra LT, Wakkie T, Busch OR, Gouma DJ, Beuers U, van Gulik T. Predictors of posthepatectomy ascites with or without previous portal vein embolization. Dig Surg. 2012; 29(6):468-74.

39. Campbell MS, Brensinger CM, Sanyal AJ, Gennings C, Wong F, Kowdley KV, et al. Quality of life in refractory ascites: transjugular intrahepatic portalsystemic shunting versus medical therapy. Hepatology. 2005; 42(3):635-40.

40. Yamamoto J, Nagai M, Smith B, Tamaki S, Kubota T, Sasaki K, et al. Handassisted laparoscopic splenectomy and devascularization of the upper stomach in the management of gastric varices. World J Surg. 2006; 30(8):1520-5. 